\title{
Seeking order out of global health chaos
}

Previously published at www.cmaj.ca

$\mathrm{I}$ t's as if basketball, football and soccer games were being played on the same surface, simultaneously.

Dr. Frances Collins, director of the United States National Institutes of Health, called it complex and confusing. Dr. Tikki Pang, director of research policy and cooperation for the World Health Organization (WHO), calls it anarchy.

In the field of global health, Pang says, there were 40 bilateral donors, 26 United Nations agencies, 20 global and regional funds, 90 global health initiatives, over 14000 global health missions, as well an untold number of not-forprofit organizations, charities, product development partnerships and other agencies operating in 54 recipient countries in 2008. Collectively, they have an annual budget of US\$22 billion. "And there are new initiatives coming on line, including the UN Secretary General's Global Strategy for Women and Children," he adds.

Moreover, many of those players on the global health scene, said several delegates to a "Global Health Governance - Multiple Players, Multiple Visions: Challenges and Opportunities" session at the World Health Summit in Berlin, Germany, are operating with different agendas, different reporting requirements and different timetables.

It's created a situation in which doctors in sub-Saharan Africa spend as much time filling out reports for various global health bodies as they spend with their patients, while nurses and other health workers compete with one another to direct more money toward AIDS or malaria or another disease, depending on which global initiative they work for, said Dr. Rose Leke, director of the biotechnology centre and professor of immunology and biomedical sciences at the University of Yaounde in Cameroon.

The Cameroon government is contemplating a move to curb the competitive nature of global health programs at the ground level by restructuring the health care system to appoint local "community health workers" who will

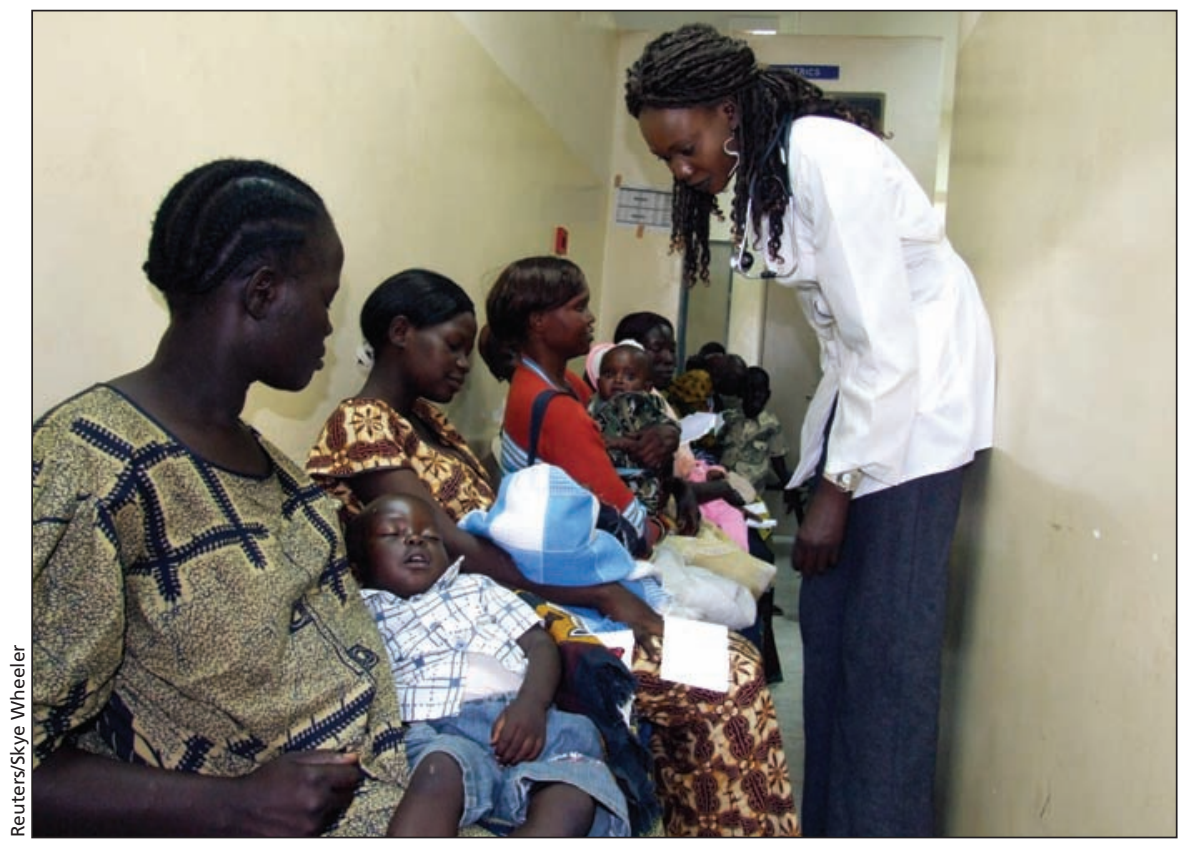

The chaos of governance in global health has created a situation in which doctors in sub-Saharan Africa spend as much time filling out reports for various global health bodies as they spend with their patients.

be in charge of delivering the goods, so to speak, for all global initiatives, Leke said. "All these workers will be paid the same salary and fee," she added. "How (global) funders will react is unclear."

Panelists and delegates argued that such anomalies point to the need for greater coordination of the global health effort to prevent duplication, reduce red tape and improve patient outcomes.

But panelist Dr. Pier Piot, director of the London School of Hygiene and Tropical Medicine in the United Kingdom promptly raised the spectre of totalitarianism.

"I applaud the multitude of actors" and "embrace pluralism," said Piot, who until a few months ago was one of the heaviest hitters on the global health scene as executive director of the Joint United National Programme on HIV/AIDS.

"Consider the alternative ... a monopoly by some organization. That would probably be highly inefficient. Twenty years after the (Berlin) wall, there is no desire for that. If you align everything to one agenda, then the real question is: Who is going to drive the agenda and impose their view on how the world should function? Is that what we want? I don't think so."

Director of Global Health Affairs for the United States Department of Health and Human Services Dr. Nils Daulaire countered that the concept of greater coordination of global health programs did not necessitate forms of micromanagement. "One of the fundamental precepts of chaos theory," he noted, is that it is perfectly legitimate to "establish boundary conditions."

Several delegates noted that the 2005 Paris Declaration, in which more than 100 foreign aid ministers, directors of agencies and other global officials committed to increased "harmonization, alignment and managing aid for results," as well as the 2008 Accra Agenda for Action (which was built on the declaration), were essentially an outright failure.

Among solutions proposed during the session were the creation of ad hoc committees with representatives from all stakeholders (governments, industry, academia, foundations, not-forprofit organizations, etc.) built around specific diseases. Others suggested 
"temporary coalitions around specific issues," or that the G-8, G-20 or WHO take a great role in setting priorities and oversight of the global health agenda, including the amount of money being targeted at any specific disease.

Daulaire said there is a "substantive need for reform and streamlining within WHO" to transform it into some form of "thought setting" body, which would be responsible for "setting global health priorities and global rules that we need to follow."

But Pang said in an interview that such a coordination role was not set out for the WHO when governments created the agency. "That is a de facto role that everyone looks at us to do. But at the same time, the way we are structured at the moment does not allow us to do that effectively. You must remember, we are a political organization. At the end of the day, we answer to member-states. To say that countries cannot control the organization, that just flies against the constitution. The only way that can happen is from member-states themselves."

Leke said another rationale for improved coordination of the global health programs can be found in the fact that funds are directed to some countries for such political reasons as previous colonial ties, rather than incidence of a specific disease within their borders. Global health aid and "governance should ignore geographical boundaries," she said.

While arguing for a concerted international effort to establish a global program for noncommunicable and chronic diseases, Dr. Srinath Reddy, president of the Public Health Foundation of India, said that it will be critical for the UN "to get its act together" with other international agencies to prevent a situation in which various agencies go into developing countries and provide conflicting advice on implementation of anything like a chronic diseases fund. To that end, Reddy advocated the creation of some sort of "consulting platform," again with representatives from all parties. "But this platform cannot be dominated by any one of the sectors," he stressed. - Wayne Kondro, CMAJ

DOI:10.1503/cmaj.109-3701

\section{Preunar 13 \\ Pneumococcal 13-valent Conjugate Voccine (Diphtheria CRM Prip Protein)}
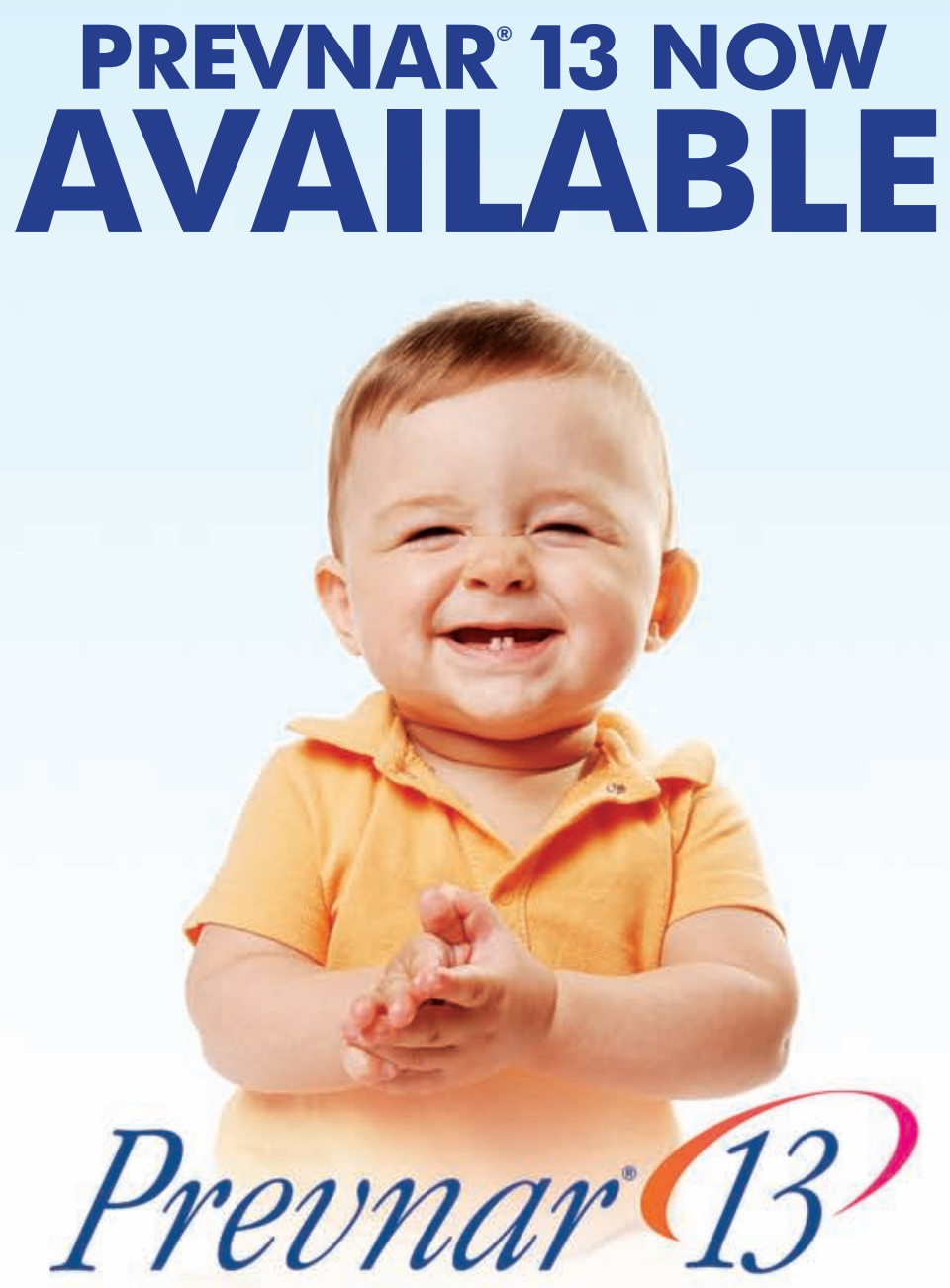

Prevnar 13 is indicated for the active immunization against Streptococcus pneumoniae serotypes $1,3,4,5,6 \mathrm{~A}, 6 \mathrm{~B}, 7 \mathrm{~F}, 9 \mathrm{~V}, 14,18 \mathrm{C}, 19 \mathrm{~A}, 19 \mathrm{~F}$ and $23 \mathrm{~F}$ causing invasive pneumococcal disease, including:

- Sepsis, meningitis, bacteraemic pneumonia, pleural empyema and bacteraemia

- Indicated for use in infants and children from 6 weeks through 5 years of age

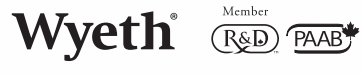

() 2010 Wyeth Canada
Montréal, Canada H4R 1 J6 